www.jmscr.igmpublication.org

Index Copernicus Value: 79.54

ISSN (e)-2347-176x ISSN (p) 2455-0450

crossref DOI: https://dx.doi.org/10.18535/jmscr/v7i4.33

\title{
Caudal epidurals compared with selective nerve root block as treatment for radicular nerve pain
}

\author{
Authors \\ Dr Bias Dev, Dr Simriti*, Dr Shiv Kumar, Dr Shalinder Sharma \\ Department of Orthopaedics, GMC Jammu, J \& K \\ *Corresponding Author \\ Dr Simriti \\ Department of Anatomy, GMC Jammu, J\& K, 180001, India
}

\begin{abstract}
The radiating pain to legs in case of prolapsed intervertebral disc disease is a disabling symptom which can last up to variable duration with majority of patients having resolution within 12 weeks and it's this period which demand a effective treatment, for which selective nerve root blocks appear to be superior than caudal epidurals.

Keywords: Selective Nerve Root Block, caudal epidural, Radicular Pain.
\end{abstract}

\section{Introduction}

Caudal epidurals has been used as pain relieving modality for lumbar radicular pain since $1901^{[1]}$. Subsequently various authors reported satisfactory results ranging from $10 \%$ to $60 \%^{[2,3]}$. Selective nerve root blocks, initially used as diagnostic modality later on has established themselves as pain reliving modality with satisfactory results being reported in approx. half of patients ${ }^{[4]}$.

The physical pressure and chemical mediators are believed to be the causative reasons for the radicular pains. The steroid through caudal epidural selective nerve root blocks are believed to reduce chemical neuritis as disc root interface. The hypersensitivity of sodium channels are believed to be decreased by selective nerve root blocks $^{[5]}$. The epidural blocks are often performed as OPD procedure but being largely blind has unsure efficacy ${ }^{[6]}$. The selective nerve root blocks by being able to deliver drug at a particular root are more effective, but needs operation theatre as well as image intensifier.

In this study the efficacy of these two procedures has been compared.

\section{Material \& Methods}

30 patients each with only radicular pain in leg secondary to prolapsed intervertebral disc were alternately subjected to caudal epidural and selective nerve root block by a single surgeon from January 2017 to Dec 2017.

The patients having lumbar canal stenosis, multiple level disease and neurological deficit were excluded. Patients with VAS 6 or more than 6 were offered the procedure. Post procedure VAS was assessed on day one, One month and six months. 
Caudal epidural was performed in minor OT setting in OPD. After prepping and draping A needle was inserted through sacral hiatus and a mixture of $8 \mathrm{ml} 2 \%$ xylocaine, $80 \mathrm{mg}$ depomedrol ( $2 \mathrm{ml}$ solution) diluted with additional $10 \mathrm{ml}$ norlal saline was injected slowly in five minutes. Patient was send to home after one hour. Patients Vas was asked telephonically on day one and in OPD or telephonically after one month and at six months. Services of anatomist were utilized in refreshing the anatomy of sacral hiatus, and ten sacra were covered with a half inch sponge covered with a cotton sheet and feel of the sacral hiatus was repeatedly practiced.

Selective nerve root were given in operation theatre under image intensifier. $3 \mathrm{ml}$ Xylocaine 2 $\%, 2 \mathrm{ml}$ depomderol (80 $\mathrm{mg})$ were injected transforaminally at desired level. Patient were send after two hours, once the effect of anaesthetic agent was over.

Both the procedures were compared for their efficacy calculating mean Vas at one month and six months.

\section{Results and Discussion}

The results are charted below

\begin{tabular}{|c|c|c|c|c|c|c|c|c|c|}
\hline & \multicolumn{4}{|c|}{ GROUP A (EPIDURAL) } & & \multicolumn{4}{|c|}{ GROUP B (NERVE BLOCK) } \\
\hline $\begin{array}{l}\text { Patient } \\
\text { ID }\end{array}$ & $\begin{array}{c}\text { Pre OP } \\
\text { PS }\end{array}$ & Post OP PS & $\begin{array}{c}1 \\
\text { Month }\end{array}$ & 6 Month & $\begin{array}{l}\text { Patient } \\
\text { ID }\end{array}$ & Pre OP PS & Post OP PS & $\begin{array}{c}1 \\
\text { Month }\end{array}$ & $\begin{array}{c}6 \\
\text { Month }\end{array}$ \\
\hline 1 & 8 & 8 & 8 & 8 & 1 & 8 & 0 & 1 & 2 \\
\hline 2 & 9 & 4 & 2 & 5 & 2 & 8 & 0 & 0 & 0 \\
\hline 3 & 7 & 7 & 7 & 7 & 3 & 7 & 0 & 2 & 6 \\
\hline 4 & 8 & 4 & 2 & 4 & 4 & 9 & 0 & 0 & 0 \\
\hline 5 & 9 & 3 & 1 & 0 & 5 & 7 & 0 & 0 & 0 \\
\hline 6 & 7 & 7 & 4 & 5 & 6 & 8 & 0 & 3 & 8 \\
\hline 7 & 8 & 8 & 8 & 8 & 7 & 7 & 6 & 7 & 8 \\
\hline 8 & 7 & 7 & 7 & 7 & 8 & 9 & 0 & 0 & 0 \\
\hline 9 & 7 & 3 & 1 & 0 & 9 & 7 & 5 & 7 & 8 \\
\hline 10 & 9 & 4 & 2 & 7 & 10 & 8 & 0 & 0 & 0 \\
\hline 11 & 9 & 9 & 9 & 9 & 11 & 7 & 4 & 5 & 8 \\
\hline 12 & 8 & 3 & 2 & 6 & 12 & 9 & 0 & 2 & 1 \\
\hline 13 & 8 & 8 & 4 & 5 & 13 & 8 & 1 & 2 & 2 \\
\hline 14 & 7 & 2 & 0 & 0 & 14 & 7 & 0 & 1 & 0 \\
\hline 15 & 7 & 7 & 4 & 6 & 15 & 9 & 3 & 4 & 1 \\
\hline 16 & 7 & 3 & 1 & 6 & 16 & 7 & 0 & 0 & 0 \\
\hline 17 & 8 & 8 & 5 & 4 & 17 & 8 & 2 & 1 & 1 \\
\hline 18 & 8 & 3 & 1 & 6 & 18 & 9 & 0 & 0 & 1 \\
\hline 19 & 9 & 9 & 9 & 9 & 19 & 7 & 0 & 1 & 1 \\
\hline 20 & 7 & 2 & 0 & 4 & 20 & 9 & 3 & 2 & 8 \\
\hline 21 & 8 & 4 & 2 & 7 & 21 & 8 & 4 & 2 & 2 \\
\hline 22 & 9 & 9 & 9 & 9 & 22 & 9 & 0 & 1 & 0 \\
\hline 23 & 7 & 7 & 7 & 7 & 23 & 8 & 2 & 1 & 1 \\
\hline 24 & 8 & 2 & 0 & 0 & 24 & 9 & 0 & 0 & 0 \\
\hline 25 & 9 & 9 & 4 & 6 & 25 & 7 & 1 & 2 & 2 \\
\hline 26 & 9 & 9 & 9 & 9 & 26 & 9 & 0 & 0 & 0 \\
\hline 27 & 7 & 2 & 1 & 0 & 27 & 8 & 0 & 0 & 0 \\
\hline 28 & 9 & 4 & 2 & 1 & 28 & 9 & 0 & 2 & 9 \\
\hline 29 & 9 & 9 & 9 & 9 & 29 & 7 & 4 & 6 & 8 \\
\hline 30 & 8 & 2 & 0 & 0 & 30 & 7 & 0 & 2 & 4 \\
\hline MEAN & 8 & 5.53333333 & 4 & 5.133333 & & 7.966667 & 1.16666667 & 1.8 & 2.7 \\
\hline
\end{tabular}


Fig 1: Comparison of Caudal epidurals with selective nerve root block as treatment for radicular nerve pain

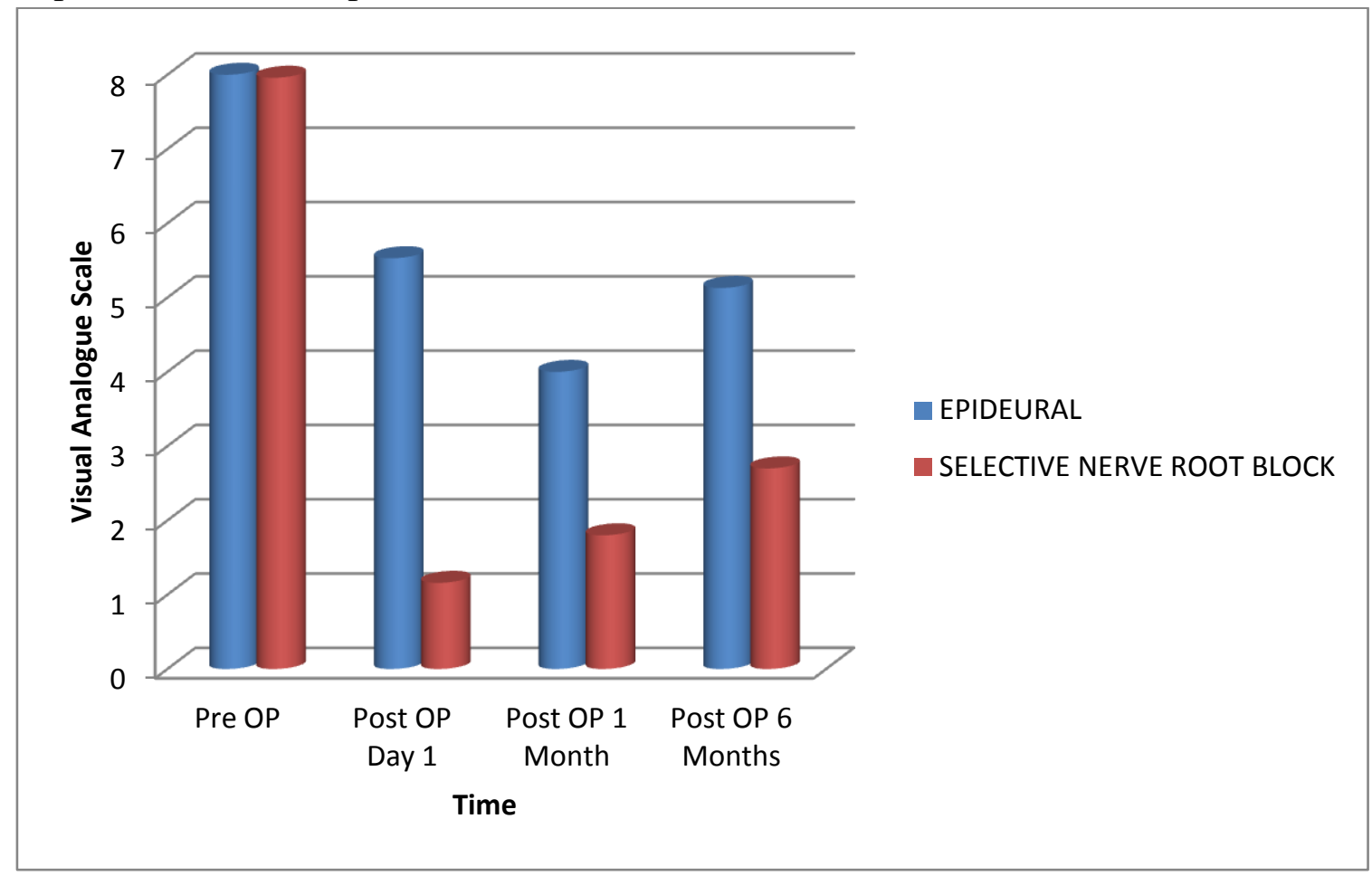

The average age of the patients subjected to caudal epidurals were 44.6 years and the average age of the selective nerve block group was 44 years. The average pre procedure pain duration was 20 days in both the groups.

The average pre procedure VAS was 8 for both the groups. Post procedure average VAS on day one, one month and six months was 3.55,4.3 and 5.13 .

The average post procedure VAS was $1.13,1.8$ and 2.7 on day one, one month and at six months. The prolapsed inter vertebral disc meets its natural history of resolution and in aprox $70 \%$ of patients the pain decreases by $8-12$ weeks and the modalities of pain reduction are of more value during this period to tide over the pain. Epidurals owing to its simplicity are more commonly used procedure than selective nerve root blocks.

The prolapsed inter vertebral disc causes pain because of chemical neuritis caused by chemical mediators released from nucleus pulposus like interleukins and TNFs. Physical pressure of as low as $4 \mathrm{~mm}$ causes venostasis, which initiates the pain because of accumulation of metabolites and fluid extravasation. The fluid extravasations and inflammation leads to fibrosis at disc root interface causing decreased mobility of nerve root which further causes pain. The steroid (methylpredinsolone) helps in decreasing the inflammation and xylocaine $2 \%$ helps by desensitizing sodium channel of dorsal root ganglion. The epidural space is a large potential space outside the dural sac and the possibility of drug containing fluid dissipiationg between it and the inner wall of vertebral column is uncertain and so the results of this procedure were lower as compared to selective nerve root block. Authors has conducted a study on dry human sacras and has found that the sacral hiatus is not anatomically uniform in all subjects and so even after good amount of practice of feeling the hiatus cannot assure correct placement of the needle , making the results uncertain in the epidural group ${ }^{[7,8,9]}$. Since the dural sac extends up to S2 vertebrae, there is tendency from the surgeon not to puncture dura inadvertently and may stay short of epidural space by being overcautious, again not delivering the drug in the desired epidural space, thus compromising the results ${ }^{[10]}$.

The factors of uncertain drug delivery in case of epidurals can be negated by transforaminal selective nerve root blocks, which deliver the 
desired drug at the disc root interface and can also be called as selective epidurals. The better results of this procedure in this study as well as reported by various authors as compared to epidurals is a testimony of its efficacy, though it require better training, operation theatre and image intensifier for executing the procedure which can become a limitation at times.

\section{Conclusion}

The pain in prolapsed intervertebral disc is self limiting a large group of patients and the pain relieving modality is most important when the pain is at its peak. The caudal epidurals though are very simple to give to patients but results of the selective nerve root blocks are superior to it, although technically difficult.

\section{References}

1. Waurick K, Waurick R. History and Technique of Epidural Anaesthesia. Anasthesiol Intensivmed Notfallmed Schmerzther. 2015 Jul;50 (7-8):476-82.

2. Bucklin BA, Hawkins JL, Anderson JR, Ullrich FA. Obstetric anesthesia workforce survey: Twenty-year update. Anesthesiology 2005;103:645-653

3. Doughty A. Walter Stoeckel (1871-1961): A pioneer of regional analgesia in obstetrics. Anaesthesia. 1990;45:468-471

4. Pal DR, Rahman MD. Ashfaqur. Morphomtric study of Sacral Hiatus: A basis for successful caudal epidural block. Bangladesh Journal of Anatomy, 2012; Vol.10 : 5-10

5. Eckel TS, Bartynski WS. Epidural steroid injections and selective nerve root blocks. Tech Vasc Intery Radiol,2009 mar;12(1);11-21.

6. Dr Simriti, Dr Bias Dev, Dr Vijay Vikas and Dr Sunanda Raina. Variations in Sacral Hiatus: Important Reason of Failure Of Caudal Epidurals. International Journal of Advanced Research (2015), Volume 3, Issue $10,957-958$.

7. Dr Simriti, Dr Bias Dev, Dr Deepa Hans and Dr SunandaRaina. Morphology of Sacral Hiatus In Dogra Region of India . International Journal of Advanced Research (2015), Volume 3, Issue 10, 605 - 609 .

8. Trotter M. Variations of the sacral canal: Their significance in the administration of caudal analgesia. Anaesthesia Analg,1947; 26(5): 192-202.

9. Aggarwal A, Gupta RN and Singh PJ. Anatomic consideration of caudal epidural space: a cadaver study.Clinical Anatomy, 2009 Sep; 22 (6):730-31.

10. Koes BW, Scholten RJ, Mens JM, Bouter LM. Efficacy of epidural steroid injections for low-back pain and sciatica: A systematic review of randomized clinical trials. Pain 1995;63:279-88. 